strategy to attract and retain doctors in rural areas. Bull World Health Organ. 2010;88(5):371-8.

5. Schneider MC, Castillo-Salgado C, Bacallao J, Loyola E, Mujica OJ, Vidaurre M, et al. Métodos de medición de las desigualdades de salud. Rev Panam Salud Publica. 2002;12(6):398-415.

Correspondencia: Percy Mayta-Tristán

Dirección: Av. Brasil 2169, Dpto 802, Jesús María, Lima, Perú.

Teléfono: (51) 987532133

Correoelectrónico:percy.mayta@upc.edu.pe

\section{MEDICIÓN Y MAGNITUD DEL BULLYING EN PERÚ}

\section{MEASUREMENT AND MAGNITUDE OF BULLYING IN PERU}

\section{Carla Cobián-Lezama1,a, Ayar Nizama-Vía ${ }^{1,2, a}$, David Ramos-Aliaga ${ }^{1, a}$, Percy Mayta-Tristán ${ }^{1, b}$}

Sr. Editor. El bullying es un problema de salud pública que incluye a tres actores: la víctima, el victimario/ agresor y el observador, y es un hecho que está cada vez más presente en nuestra sociedad, pues se discute sus implicancias en escenarios de salud, educación y hasta en la prensa. Sin embargo, la información científica disponible sobre la magnitud del bullying en el Perú (Tabla 1) muestra prevalencias bastante elevadas y hasta alarmantes, por lo que es válido preguntarse si es que el bullying en el Perú se está midiendo de manera correcta.

La definición del bullying victimización incluye tres características que deben cumplirse siempre: debe haber un desbalance de poder en favor del agresor, debe existir una intención de hacer daño y, finalmente, debe ser sistemático; es decir, repetido en el tiempo (1). Por ello, las escalas que se usan para medirlo deben tener en cuenta estos aspectos, de lo contrario se podría

\footnotetext{
1 Escuela de Medicina, Universidad Peruana de Ciencias Aplicadas. Lima, Perú

2 Sociedad Científica de Estudiantes de Medicina, Universidad Peruana de Ciencias Aplicadas. Lima, Perú

a Estudiante de medicina; ${ }^{\text {b }}$ Médico salubrista

Recibido: 09-10-14 Aprobado: 15-10-14
}

Citar como: Cobián-Lezama C, Nizama-Vía A, Ramos-Aliaga D, MaytaTristán P. Medición y magnitud del bullying en Perú [carta]. Rev Peru Med Exp Salud Publica. 2015;32(1):196-7. cometer un error al medir agresiones esporádicas y catalogarlas como bullying.

Al revisar la bibliografía peruana sobre estudios de bullying se ha evidenciado que los diferentes autores utilizan básicamente dos escalas para evaluar este fenómeno, estas son la escala de DEVIDA (2) y la de Oliveros ${ }^{(3)}$. La escala de DEVIDA en su versión 2012 incluye 14 situaciones de violencia durante el último año y considera que cuando presenta tres o más características hay bullying moderado. Oliveros generó una escala en el 2007 que evalúa 9 situaciones de violencia durante el último año y considera bullying cuando presenta dos o más características. Ambas escalas no consideran el elemento sistemático como parte de la definición de bullying, además, ninguna cuenta con un estudio formal de validación, por lo tanto, no existe garantía de que midan realmente bullying.

Incluso, en algunos casos a pesar de usar la misma escala, algunos autores han creado definiciones operativas distintas, por lo que los valores de prevalencia reportados no miden lo mismo (Tabla 1), pues usan diferente número de situaciones de violencia, y las temporalidades (último año, durante la secundaria, sin mención de la temporalidad) son diferentes, por lo que la magnitud del fenómeno bullying en los estudios peruanos no es clara. Por ello, existe una diferencia grande entre los reportes de países europeos donde la prevalencia de bullying varía entre 10 a $20 \%{ }^{(4)}$ y los estudios peruanos entre 35 a $60 \%$.

Esta situación impide la comparación entre estudios, y sus prevalencias, lo que dificulta un diagnóstico global y limita la posibilidad de desarrollar estrategias o asignar recursos para intervenciones futuras en las poblaciones más afectadas. Así mismo, el contar con una medición estándar permitiría evaluar en el tiempo el impacto de dichas intervenciones y elegir las más efectivas.

La comunidad científica que estudia el bullying en el Perú, debe generar escalas que incluyan el comportamiento sistemático y una temporalidad clara, o traducir y adaptar culturalmente escalas generadas en inglés que además permitirían compararnos con otras realidades ${ }^{(5)}$. De esta manera se podrá tener una prevalencia más certera que refleje la realidad en nuestro país.

Conflictos de interés: no existen conflictos de interés en la publicación de este artículo 
Tabla 1. Diferencias en las definiciones y resultados de las mediciones del bullying en el Perú

\begin{tabular}{|c|c|c|c|}
\hline Estudio & $\begin{array}{c}\text { Escolares y } \\
\text { colegios }\end{array}$ & Definición operativa de bullying & Resultados / temporalidad \\
\hline $\begin{array}{l}\text { DEVIDA } 2013{ }^{(2)} \\
\text { IV Estudio Nacional de Prevención y } \\
\text { Consumo de Drogas en estudiantes } \\
\text { de secundaria } 2012\end{array}$ & $\begin{array}{l}48025 \text { escolares } \\
\text { de secundaria. } \\
\text { Colegios: } 416\end{array}$ & $\begin{array}{l}\text { Escala DEVIDA, } 14 \text { situaciones de } \\
\text { violencia en el último año. Bullying por } \\
\text { niveles: } 0 \text { - 2: bajo; } 3 \text { - 6: medio; } 7 \text { - 10: } \\
\text { alto. }\end{array}$ & $\begin{array}{l}\text { Prevalencia de victimización } \\
\text { en el último año: } \\
\text { bajo: } 61,3 \% \\
\text { medio: } 27,6 \% \\
\text { alto: } 11,1 \%\end{array}$ \\
\hline $\begin{array}{l}\text { Romaní } \mathbf{2 0 1 1} \text { (a) } \\
\text { Autorreporte de agresividad escolar } \\
\text { y factores asociados en escolares } \\
\text { peruanos de educación secundaria }\end{array}$ & $\begin{array}{l}65041 \text { escolares } \\
\text { de secundaria. } \\
\text { Colegios: } 516\end{array}$ & $\begin{array}{l}\text { Escala DEVIDA, se consideró agresión } \\
\text { cuando comete tres o más tipos de } \\
\text { situaciones de violencia durante sus } \\
\text { estudios de secundaria. Se categorizó } \\
\text { agresión: } 10-14 \text { : severa; 6-9: moderada; } \\
\text { 3-5: leve. }\end{array}$ & $\begin{array}{l}\text { La prevalencia de } \\
\text { agresividad durante la } \\
\text { secundaria fue de } 37,5 \% \text { y } \\
\text { la frecuencia de agresividad } \\
\text { severa fue de } 10,3 \%\end{array}$ \\
\hline
\end{tabular}

\begin{tabular}{|c|c|c|c|}
\hline $\begin{array}{l}\text { Romaní } \mathbf{2 0 1 0} \text { (b) } \\
\text { Autorreporte de victimización escolar } \\
\text { y factores asociados en escolares } \\
\text { peruanos de educación secundaria, } \\
\text { año } 2007\end{array}$ & $\begin{array}{l}65041 \text { escolares } \\
\text { de secundaria } \\
\text { Colegios: } 516\end{array}$ & $\begin{array}{l}\text { Escala DEVIDA, se consideró } \\
\text { victimización cuando sufre tres o más } \\
\text { tipos de situaciones de violencia (de } \\
14 \text { tipos) durante sus estudios de } \\
\text { secundaria. }\end{array}$ & $\begin{array}{l}\text { Prevalencia de victimización } \\
\text { durante la secundaria: } \\
56,4 \% \text {. }\end{array}$ \\
\hline $\begin{array}{l}\text { Oliveros } 2009 \text { (c) } \\
\text { Intimidación en colegios estatales de } \\
\text { secundaria del Perú }\end{array}$ & $\begin{array}{l}1633 \text { escolares } \\
\text { de } 1 .^{\circ} \text { a } 5 .^{\circ} \text { de } \\
\text { secundaria. } \\
\text { Colegios: } 5\end{array}$ & $\begin{array}{l}\text { Escala de Oliveros, se consideró } \\
\text { bullying cuando se señalaban dos o más } \\
\text { ítems como positivos (de nueve ítems), } \\
\text { en el último año. }\end{array}$ & $\begin{array}{l}\text { Incidencia* de bullying ha } \\
\text { sido de } 50,7 \% \text {. }\end{array}$ \\
\hline $\begin{array}{l}\text { Amemiya } 2009 \text { (d) } \\
\text { Factores de riesgo de violencia } \\
\text { escolar (bullying) severa en colegios } \\
\text { privados de tres zonas de la sierra } \\
\text { del Perú }\end{array}$ & $\begin{array}{l}736 \text { escolares } \\
\text { entre quinto de } \\
\text { primaria y quinto de } \\
\text { secundaria. } \\
\text { Colegios: no refiere }\end{array}$ & $\begin{array}{l}\text { Escala de Oliveros, se consideró } \\
\text { bullying cuando se señalaban dos o más } \\
\text { ítems como positivos (de } 9 \text { ítems) en el } \\
\text { último año. } \\
\text { Se categoriza: leve: } 2 \text {, moderado: } 3-4 \text {, } \\
\text { severo: cinco o más. }\end{array}$ & $\begin{array}{l}\text { El } 47,4 \% \text { tuvo bullying, de } \\
\text { estos } 10,6 \% \text { ( } 37 \text { alumnos) } \\
\text { presentó bullying severo. }\end{array}$ \\
\hline $\begin{array}{l}\text { Oliveros } 2008 \text { (e) } \\
\text { Violencia escolar (bullying) en } \\
\text { colegios estatales de primaria en el } \\
\text { Perú }\end{array}$ & $\begin{array}{l}916 \text { escolares } \\
\text { de } 1 .^{\circ} \text { a } 6 .^{\circ} \text { de } \\
\text { primaria. } \\
\text { Colegios: } 4\end{array}$ & $\begin{array}{l}\text { Escala de Oliveros. No se menciona } \\
\text { la definición de bullying; por estudios } \\
\text { posteriores se infiere que es } 2 \text { de } 9 \\
\text { ítems en el último año. }\end{array}$ & $\begin{array}{l}\text { Incidencia* de bullying de } \\
47 \% \text {. }\end{array}$ \\
\hline $\begin{array}{l}\text { Oliveros } 2007 \text { (3) } \\
\text { Incidencia y factores de riesgo de la } \\
\text { intimidación (bullying) en un colegio } \\
\text { particular de Lima-Perú }\end{array}$ & $\begin{array}{l}185 \text { escolares de } 4 .^{\circ} \\
\text { de primaria a } 5 .^{\circ} \text { de } \\
\text { secundaria. } \\
\text { Colegios: } 1\end{array}$ & $\begin{array}{l}\text { Creación de escala de Oliveros, mide } \\
\text { nueve conductas de intimidación en el } \\
\text { último año. No definición de bullying; por } \\
\text { estudios posteriores se infiere que es dos } \\
\text { de nueve ítems. }\end{array}$ & $\begin{array}{l}\text { Incidencia* de Bullying } \\
\text { (Intimidación): } 54,7 \% \text {. }\end{array}$ \\
\hline
\end{tabular}

\section{REFERENCIAS BIBLIOGRÁFICAS}

1. Gini G, Pozzoli T, Lenzi M, Vieno A. Bullying victimization at school and headache: a meta-analysis of observational studies. Headache. 2014 Jun;54(6):976-86. doi: 10.1111/ head.12344.

2. Comisión Nacional para el Desarrollo y Vida sin Drogas. IV estudio nacional de prevención y consumo de drogas en estudiantes de secundaria 2012. Lima: DEVIDA; 2013.

3. Oliveros M, Barrientos A. Incidencia y factores de riesgo de la intimidación (bullying) en un colegio particular de LimaPerú, 2007. Rev Peru Pediatr. 2007; 60(3):150-5.
4. Due P, Holstein BE, Lynch J, Diderichsen F, Gabhain SN, Scheidt $\mathrm{P}$, et al. Bullying and symptoms among school-aged children: international comparative cross sectional study in 28 countries. Eur J Public Health. 2005 Apr;15(2):128-32.

5. Hamburger ME, Basile KC, Vivolo AM. Measuring bullying victimization, perpetration, and bystander experiencies: a compendium of assessment tools. Atlanta: CDC; 2011.

Correspondencia: Ayar Nizama Via

Dirección: Calle Tomás Ramsey 904 Dpto. 203, Lima, Perú

Teléfono: 980081488

Correo electrónico:ayar.nv@gmail.com 